\title{
O Colégio Jesuíta no contexto do Século XVI: Formação De Um Novo Homem
}

\section{The Jesuit school in the context of the sixteenth century: forma- tion of a new man}

Fernanda Santos*

\begin{abstract}
Resumo: A partir do século XVI, os colégios religiosos iniciam a sua tentativa de formar mestres e discípulos dentro do ideário religioso preconizado e dentro de uma lógica contrarreformista. A Companhia de Jesus foi uma das Ordens que mais apostou no ensino, defendendo que a educação do jovem podia promover uma nova sociedade católica. Assim, a Ordem recorreu, como estratégia de evangelização, a utilização de instrumentos normativos e homogeneizadores, tais como a Ratio Studiorum, ou o uso do modus parisiensis. De acordo com Durkheim (1955), cada sociedade constrói um modelo de homem ideal, quer do ponto de vista intelectual, quer do ponto de vista físico e moral. Esse ideal, ao mesmo tempo uno e diverso, constitui a parte básica da instrução. Este artigo mostra como o colegio jesuíta inculcou normas civilizadoras, de acordo com as teorias de Norbert Elias, de forma a intervir na sociedade do seu tempo e a moldar o caracter ideal de um novo homem.
\end{abstract}

Palavras-chave: Companhia de Jesus; colégio jesuíta; novo homem; instrução; ratio studiorum

\footnotetext{
* Professora Adjunta no colegiado de Letras, da Universidade Federal do Amapá, Campus Santana, Brasil E-mail: fercris77@gmail.com
} 


\begin{abstract}
From the sixteenth century, religious colleges began their attempt to train masters and disciples preconized religious ideology and with a counterreformist logic. The Society of Jesus was one of the Orders that most bet on teaching, arguing that the education of the young could promote a new catholic society. Thus, as an evangelization strategy, the Order has used normative and homogenizing instruments, such as Ratio Studiorum and the modus parisiensis. According to Durkheim (1955), each society constructs a model of ideal man, from the intellectual, the physical and moral point of view. This ideal, at once one and diverse, constitutes the basic part of instruction. This article shows how the jesuit school inculcated civilizing norms according to the theories of Norbert Elias in order to interfere in the society of its time and to shape the ideal character of a new man.
\end{abstract}

Keywords: Counter-Reformation; jesuit college; new man; instruction; ratio studiorum

\title{
1. Introdução: a educação religiosa no século XVI
}

A partir do século XVI nasciam os corpos profissionais que se especializaram na educação, podendo tomar a forma de corporações ou congregações religiosas. Na história da educação, esta é a primeira vez que se reconhece a necessidade de preparar mestres para exercer atividades de ensino. A Ratio Studiorum, instrumento geral da educação da Companhia de Jesus, proclamava que a preparação de um corpus docente era fundamental no ensino dos jovens. A qualificação destes elementos, bem como a sua disposição e compromisso pessoais eram fundamentais para a qualidade do ensino e da propagação do programa da Ratio. ${ }^{l}$ Não significa que a profissão de professor ou o exercício de sua atividade estivesse, de algum modo, regulamentada. Conforme afirma Antônio Novoa, há que ter em conta a heterogeneidade sociológica dos mestres de leitura e de escrita do século XVI. A partir da segunda metade do século, no quadro da ação contrarreformista da Igreja católica, é esta que passa a assumir o controle dos tempos e dos lugares próprios para ensino, bem como dos agentes e das práticas pedagógicas. Tanto as autoridades eclesiásticas quanto as Ordens religiosas transformaram o ensino num meio de luta contra tudo aquilo que fosse considerado como heresia. ${ }^{2}$ Os Jesuítas apostaram na concepção e na necessidade de um conhecimento humano visando à modificação do objeto para alcançar determinados objetivos, como a conversão ou a moldagem de um novo homem. Para os jesuítas, este novo homem era um homem de fé, que engrossaria as fileiras de luta contra o protestantismo, mas também um humanista, influenciado pelas ideias renascentistas. A Ordem inaciana procurou formar exemplos deste ideal. Nas palavras de Santo Inácio de Loyola, tomado 
pela vontade de agir, mais do que de fruir, uma ação dirigida à maior glória de Deus. A Ordem integrou nas suas fileiras muitos intelectuais formados nos seus colégios, que ganharam visibilidade no seu tempo e garantiram reconhecimento notável na memória histórica por mérito da sua obra realizada e das redes de circulação de saberes criadas pelos inacianos. Tanto os colégios quanto a Ratio Studiorum não nasceram prontos com a sua configuração final. Somente depois de uma dezena de anos a Companhia de Jesus assumiu sua forma definitiva, consolidando carisma e ideário. Com o tempo e inúmeras experiências, a atividade educacional se tornou fundamental para a Ordem jesuítica compondo, historicamente, um ideário e uma racionalidade próprios ao serviço da Coroa num mundo que se expandia rapidamente. $\mathrm{O}$ conhecimento, para os inacianos, foi essencialmente fruto da prática. Os novos assuntos requeriam juízos para os quais não bastava o bom domínio das Escrituras e da tradição, necessitavam também do conhecimento das particularidades da terra, o que só seria adquirido pela experiência. ${ }^{3}$

Seguindo as teorias pedagógicas de Erasmo, Vives e outros humanistas, os Jesuítas substituíram os métodos drásticos de intimidação por intervenções sem carácter punitivo. O castigo físico tendeu cada vez mais a ser substituído por uma direção espiritual atenta, uma organização cuidada do espaço e do tempo, uma séria programação dos conteúdos e uma aplicação dos métodos de ensino que procuraram manter os alunos nos limites corretos que os estimulassem ao estudo e à conversão num ideal de católico perfeito.

O segundo plano se articulou com o conceito-chave de classe. Desse modo, o colégio assentou na ideia de inclusão de um maior número de alunos, e estes passaram a ser uma massa homogênea para ser ensinada, o que designaríamos como classe ou turma, todavia com especificidades, como a faixa etária ou o nível de conhecimentos individual. $\mathrm{O}$ agrupamento em classes sucessivas obrigou a graduar programas, a encadeá-los pelo nível de complexidade, a seccionar o tempo escolar e a subdividir o espaço. Não há registros escritos do espaço onde ocorria uma aula. A Ratio nao tem essa designaçao, aula é traduzível como sendo o salão nobre em que se realizavam os atos públicos mais solenes. Todavia, a imagem familiar que nos acompanha até aos dias de hoje, sobre o que entendemos o que é uma aula, é a de uma sala, uma classe e um professor, combinação essa que não mais será abandonada, privilegiando-se a homogeneização, em contraponto à dispersão, ao mesmo tempo que se individualizava cada aluno. António Nóvoa viu nestes aspectos as referências estruturantes do ensino e do trabalho pedagógico até aos dias de hoje, uma espécie de modelo que se impôs, ao longo do tempo, como via única. ${ }^{4}$

A Igreja Reformada deu o primeiro passo no que diz respeito ao ensino. Dominique Julia assinalou a formação cristã das crianças como uma das finalidades essenciais das Reformas (protestante e católica), e o catecismo, nascido da concorrência entre as confissões religiosas, como um fenômeno 
associado à escolarização. ${ }^{5} \mathrm{O}$ projeto da corrente cristã semimonástica identificada como Devotio Moderna teria passado diretamente para os colégios de Paris e destes, por seu turno, irradiado para muitas escolas protestantes e católicas, sobretudo através dos Jesuítas, que na capital francesa estudaram durante a primeira metade do século XVI. ${ }^{6} \mathrm{O}$ próprio surgimento da Companhia de Jesus assentou no desejo de reformar a vida e os costumes para combater os vícios, sendo que o meio mais eficaz seria começar pela educação dos jovens, ensinando-lhes a serem cristãos desde a sua tenra idade. Conceitos como piedade e virtude permearam o ensino dos Jesuítas. ${ }^{7}$

A introdução das séries e das classes escolares deu-se também nos colégios protestantes e católicos do século XVI, aperfeiçoando-se ao longo dos séculos seguintes. ${ }^{8} \mathrm{~A}$ escola atual muito deveu à matriz pedagógica dos Colégios dos Irmãos da Vida Comum, criados nos Países Baixos ainda durante o século XIV, ativos no norte da Alemanha e na Polônia até finais do século XV. As escolas dos Irmãos da Vida Comum tinham sido absorvidas pela Reforma Protestante. As suas práticas didáticas assemelham-se às dos Jesuítas. $\mathrm{O}$ valor formativo que Santo Inácio de Loyola atribuía às letras clássicas era o mesmo de Erasmo, Budé, Vives ou Tomás Moro. ${ }^{9}$ Estes contavam já com um agrupamento de alunos feito por classes, divididas por programas distintos, cada qual com seu mestre. Aqui também se praticava o chamado ensino simultâneo, no qual os alunos das primeiras classes eram ensinados pelos alunos de classes mais elevadas. Do mesmo modo, eram promovidos exames para progredir à classe superior, eram estabelecidos horários, e estimulava-se o aluno ao estudo por meio de atribuição de prémios. Philippe Ariès referiu também, que no período medieval não havia divisão de idades no mundo social, nem nas escolas, catedrais e universidades, estudantes de diferentes idades conviviam e aprendiam lado a lado. ${ }^{10}$

Os Jesuítas souberam tirar partido do espírito de emulação preconizado por Erasmo e pela pedagogia renascentista, inspirada em Quintiliano, através de concursos literários, da atribuição de prêmios e de títulos honoríficos, com exposição de poesias, enigmas e emblemas, com declamação pública diante de outra classe, de todo o colégio ou da universidade, ou mesmo de toda a cidade. A emulação garantia ainda a atividade constante destes alunos, principalmente na realização de disputas que, para serem justas, deveriam ser realizadas entre pares de adversários ao mesmo nível. O que subjaz a esta série de práticas escolares é o reconhecimento dos mecanismos cénico-didáticos nas estratégias de aprendizagem, treinando o aluno para o uso efetivo da palavra em espaços públicos, fazendo dele alguém apto para intervir na sociedade. ${ }^{11}$

\section{Colégios jesuítas: condutas e normas para a formação de um novo homem}

De acordo com Durkheim, cada sociedade constrói um modelo de 
homem ideal, quer do ponto de vista intelectual, quer do ponto de vista físico e moral. Esse ideal, ao mesmo tempo uno e diverso, constitui a parte básica da instrução, tendo por função suscitar na criança um certo número de estados físicos e mentais que a sociedade considera como indispensáveis a todos os seus membros, e que o grupo social particular (casta, classe, família, profissão) considera igualmente indispensáveis a todos que o formam. A sociedade, em seu conjunto, e cada meio social em particular, é que determinam este ideal a ser realizado. ${ }^{12} \mathrm{~A}$ Companhia de Jesus aspirou a formar uma sociedade católica, que não poderia existir sem que houvesse em seus membros certa homogeneidade. A instrução assegurou a persistência desta diversidade necessária, diversificandose ela mesma e permitindo as especializações. Do ponto de vista social, a educação não é senão o meio pelo qual a sociedade prepara, no íntimo das crianças, as condições essenciais da própria existência. ${ }^{13}$ De modo a perpetuar o carisma que subjaz à sua fundação, de evangelização global, a Companhia de Jesus trouxe um investimento massivo na instrução católica.

O século XVI assistiu a um intenso esforço de codificação e controle dos comportamentos. Na formação deste novo homem, foi importante submetê-lo às normas da civilidade, consoante a análise de Norbert Elias, que propôs pensar as transformações da sociedade no seio de um mesmo processo de civilização. Enfatizando os mecanismos de implantação e reprodução das normas sociais, o autor colocou a interiorização individual da regra como o aspecto que the confere a maior eficácia. A disciplina coletiva tornou-se, assim, objeto de uma gestão pessoal e privada. Referiu-se o autor a uma espécie de automatismo, uma autocompulsão, à qual não o indivíduo não poderia resistir, mesmo que desejasse. Isso levou à formação de uma complexa e extensa teia de ações, as quais se geriam por um aparelho automático de controle, visando prevenir as transgressões do comportamento socialmente aceitável. ${ }^{14}$ Dentro do processo educativo, este mecanismo de controle e algo intrínseco a todos os processos pedagógicos institucionalizados, ou seja, a todas as formas de escolarização. ${ }^{15}$

Os textos do século XVI codificaram minuciosamente os valores corporais e regulamentaram em detalhes o sistema dos comportamentos sociáveis. Toda a documentação normativa descreveu condutas prescritas e não condutas reais, cujas finalidades foram sociais e pedagógicas. Os textos revelaram a mesma vontade de expor e ensinar as maneiras legítimas de comportamento. No entanto, realizaram esse projeto de modos bem diversos, segundo a importância que atribuíam às regras de conduta, segundo o público ao qual se destinavam, segundo as formas de aprendizagem que sugeriam. ${ }^{16}$

No esteio deste pensamento, criaram-se lugares próprios de instrução e de educação, para transformar e moldar as vontades, assim como para preservar os jovens de condutas inapropriadas, inscrevendo-os num espaço moral e neutralizador do exterior, onde se poderia exercer continuamente a vigilância. ${ }^{17}$ A tentativa de colocar em marcha um modelo universal de educação, 
a partir do século XVI, convocava um modelo pedagógico que só se pode conceber em função de uma clientela determinada, sabendo que a educação deveria ser adequada à futura posição social. A instituição educativa deveria assegurar a instrução e a socialização da criança. Esta tarefa não recairia na família, independentemente do seu lugar na estratificação social. O colégio deveria suprir as faltas da família, impondo um programa e uma pedagogia únicas, no seio de uma classe que reunisse todos os alunos de um mesmo nível teórico de conhecimentos. Apesar disso, no seio do colégio a estratificação social comum era sobreposta pelos méritos escolares que cada um alcançasse. Dentro da classe poderiam estabelecer-se diversos papéis, que correspondiam a diferentes cargos hierárquicos, de acordo com o reconhecimento do mérito do aluno. ${ }^{18}$

\section{Colégios jesuítas e os instrumentos unificadores de ensino: a Ratio Studiorum}

Alguns traços que caracterizaram a Companhia de Jesus foram sistematizados na Ratio Studiorum de 1599, mostrando a orientação do ensino jesuítico nos séculos seguintes. A Ratio valeu como instrumento educativo, contendo a experiência dos Jesuítas ao longo de quase cinquenta anos. Aplicada à instrução, era um instrumento que se destinava a assegurar a unidade de pensamento e de ação. Desde 1547 que a Companhia vinha acumulando informações sobre o andamento da catequese e do ensino em todas as missões. A partir de 1581 o padre Cláudio Aquaviva, geral da Companhia de Jesus, nomeou uma comissão de doze padres para reformular os estudos nas instituições educativas da Companhia. Em 1583 reuniram-se em Roma. Os colégios tinham já um plano de estudos em Humanidades que, em alguns deles, era já classificada como Ratio ou regulamento interno. É o caso do regulamento do Colégio de Messina, que existia desde 1548, ou do Colégio Romano, desde 1560, que fora enviado para Roma. O documento-síntese ficou pronto em 1591, recebendo emendas até à data de 1598, sendo publicado em Nápoles, em janeiro de $1599 .{ }^{19}$

A Comissão examinou cartas e consultas recebidas de Espanha, França, Alemanha, Itália, Portugal, juntamente com estatutos e leis de colégios e universidades, principalmente o livro manuscrito do Colégio Romano. A Comissão apresentou dois textos em agosto de 1585: um deles, De Delectu Opinionum, era um conjunto de 597 proposições extraídas da Suma Teológica, de São Tomás de Aquino. As proposições deveriam ser tidas em conta pelos professores da Ordem. O outro tratado, Praxis et Ratio Studiorum estipulava as matérias a serem ensinadas. Começando pela Teologia (Escritura Santa, Teologia Escolástica, Controvérsia, Casos de Consciência), passava pela Filosofia e Humanidades, até chegar ao mais básico de todos os cursos, infima 
grammatica, a classe inicial de Latim. A Ratio prescrevia o estudo de São Tomás de Aquino na Teologia Escolástica, seguindo os doutores aprovados pelas universidades católicas.

Um dos grandes desafios propostos à Igreja católica foi exatamente a divisão fraturante da Europa, por razões de confessionalidade, entre protestantismo e catolicismo, e com expressões políticas diversas. ${ }^{20} \mathrm{Na}$ situação contrarreformista, os conhecimentos transmitidos pela Ratio e pelo ensino dos Jesuítas visavam a intervenção nas questões do presente. Apontava ainda para caraterísticas e virtudes cristãs, como a humildade, a modéstia, a simplicidade. O objetivo primordial da Ratio Studiorum foi sempre o da ortodoxia, seguindo-se com a máxima fidelidade a tradição canônica e os textos sagrados autorizados pela Igreja a partir do Concílio de Trento, com a finalidade de combater as heresias e converter os gentios. As normas didáticas do ensino subordinavam-se às normas disciplinares, que pressupunham a obediência à autoridade, redimensionada a partir do Concílio. ${ }^{21}$ De caráter de formação estritamente católico, a Ratio Studiorum orientava os educandos de forma que não se questionassem os principios catolicos, considerandos como verdade absoluta.

A 8 de abril de 1546 os bispos reuniram para a IV sessão do Concílio de Trento, declarando herética a tese sola fide et sola scriptura, da teologia reformada. Martinho Lutero prescrevia que o fiel devia colocar-se em contato com Deus por meio da leitura solitária da Bíblia, sem mediadores do clero, dos ritos e cerimônias visíveis na Igreja. Com relação à instrução, a Reforma tinha como base o ensino das línguas, nacionais e antigas, pois somente o conhecimento das mesmas permitiria o acesso às Sagradas Escrituras. As escolas deveriam ser organizadas pelos seguintes preceitos: línguas, obras literárias, ciências, artes, jurisprudência e medicina, nas quais os conceitos de estudo e trabalho atuariam de forma conjunta. A Reforma acabou por influenciar de forma religiosa, cultural, econômica e política a sociedade do seu tempo. ${ }^{22}$ Contra a tradição luterana, o Concílio confirmou a tradição da Igreja católica, no que diz respeito a ritos e ao governo dos fiéis.

A redefinição da Igreja como comunidade de fé e autoridade ampliou as comunidades dos fiéis, determinando que ela incluísse todas as populações gentias das terras recentemente invadidas por espanhóis e portugueses, onde as novas ordens fundadas para combater a heresia, como a Companhia de Jesus, deviam exercer o ministério da Igreja. Deste modo, a Igreja católica apostou na defesa da transmissão oral das duas fontes da Revelação, a Tradição e as Escrituras, recuperando técnicas gregas, latinas e escolásticas do discurso, como o sermão, o diálogo, a controvérsia, a disputa. A tradição autorizada era repetida na lectio dos professores dos cursos de Letras, Artes e Teologia regulados pela Ratio Studiorum. A edição de um Index, em 1558, censurou livros por forma a perpetuar esta mesma ortodoxia. ${ }^{23}$ 
O ensino nos colégios jesuítas procurou moldar o jovem estudante a logica contrarreformista: o exame de consciência através da oração, missas diárias, as doutrinas aprendidas pela memória, a vigilância constante do professor, até mesmo na seleção das leituras do aluno. O instrumento unificador da pedagogia da Companhia de Jesus, a Ratio Studiorum, apontou o caminho dos inacianos: apartar os colegiais do caminho dos vícios, mostrando-lhes o caminho da virtude. Os mestres deveriam ser exemplos a seguir. ${ }^{24}$

O colégio fez parte da produção histórica de um sujeito, neste caso o aluno, e da produção das estruturas que tentaram intervir sobre as atitudes, disposições e comportamentos dele. Assim se afirmou uma pedagogia jesuítica vinculada às competências morais do educando. Em termos educativos, o ensino nos colégios jesuítas defendeu a produção de um novo homem capaz de dar o seu contributo particular para a integração moral e cristã da sociedade, através do domínio de várias experiências e saberes. Os Jesuítas lançaram mão de uma multiplicidade de estratégias, procurando formar um sujeito em suas escolas, através dos compêndios utilizados na classe. Assinalável foi também a questão da individualização do aluno, mudança educativa que se deu entre o século XVI e finais do século XVII, a partir dos conceitos da Ratio Studiorum, que se debruçaram no conhecimento das faculdades, e das condições dos colegiais, referindo a eficácia de uma ação educativa que se adaptasse às características de cada um.

A pedagogia jesuítica adotou o método dos colégios parisienses, o modus parisiensis. $\mathrm{O}$ modus parisiensis diferenciou-se pelo fato de ensinar gramática sólida, graduar classes e cursos, implementar exercícios nas classes e procurar individualizar o aluno. Inácio de Loyola se inspirou no modus parisiensis preferindo-o ao modus italicus de ensinar. As características deste método de ensino se relacionavam com a pratica escolar utilizada na Universidade de Paris, onde os colégios estavam agregados à universidade. Dentro do modus parisiensis, a disciplina predominava, o plano de estudos estava rigorosamente determinado; as exercitações escolares que se seguiam às aulas eram frequentes; as classes eram formadas consoante o aproveitamento dos alunos; para cada classe estava designado um professor; a matéria era rigorosamente ensinada. Os alunos passavam à classe seguinte após rigoroso exame. Com efeito, os Jesuítas mantiveram na sua organização escolar um plano de progressão através da gradual complexidade das matérias. ${ }^{25}$

O modus parisiensis surgiu, efetivamente, da necessidade de os colégios de Paris se articularem com as universidades a que estavam anexados, através de suas práticas e normas pedagógicas. $\mathrm{O}$ ensino baseava-se num programa de leituras, complementado por um vasto leque de tarefas, das repetições às disputas (exercitia ou exercitationes), por meio das quais os estudantes exibiam os seus conhecimentos e o domínio das matérias. Novamente os alunos apareciam agrupados por classes, de acordo com um plano de progressão em 
níveis sucessivos de complexidade, em função da idade e dos conhecimentos. Os exames determinavam quem passava para os níveis seguintes. ${ }^{26} \mathrm{O}$ modus parisiensis esteve, assim, na origem da pedagogia jesuítica, sendo uma das suas principais fontes de inspiração. A escolha do método não foi aleatória. A primeira geração de Jesuítas tinha passado por Alcalá e Paris e conhecido de perto as principais universidades italianas, tais como Pádua, Bolonha, Roma. O o modus parisiensis se apresentava como um método de maior coerência, maior rigor, e consequentemente maior eficácia. O contraste com o sistema italiano era flagrante, apresentando ordem, rapidez na aprendizagem, exercício, disciplina. Não foi apenas Inácio de Loyola que escolheu o método, mas toda uma geração de jesuítas, contemporânea ao fundador, destacando-se Jerónimo Nadal, responsável pela aplicação do método pela Companhia de Jesus. ${ }^{27}$

Os Jesuítas imprimiram uma nova dinâmica à pedagogia do modus parisiensis, tornando os princípios e as práticas codificadas em Paris mais flexíveis e mais complexos, ao mesmo tempo que institucionalizaram modalidades associadas a programas considerados de ensino integral, mantendo em sua organização escolar um plano de progressão através da gradual complexidade das matérias. Desta forma, aprofundaram técnicas pedagógicas, tornando o professor um decifrador dos conteúdos desenvolvidos. ${ }^{28}$ As matérias deviam ser estudadas segundo uma determinada ordem: a Teologia e a Filosofia deviam ser precedidas pelos estudos das Humanidades e da Retórica, por exemplo, e dentro de cada uma destas matérias havia uma certa disposição a respeitar. Era possível um aluno menos preparado transitar, a meio do ano, para a classe anterior, a fim de consolidar os fundamentos daquela classe. Línguas (Latim, Grego e Hebraico), Humanidades, Retórica e Artes eram conhecimentos igualmente necessários para a prossecução de quaisquer outros estudos, não se podendo frequentar o Curso de Artes sem revelar boas aptidões em Humanidades e em Retórica. ${ }^{29}$

Inácio de Loyola expôs, na parte IV das Constituições que redigiu, intitulada "Como instruir nas letras e em outros meios de ajudar o próximo os que permanecem na Companhia", que a Ordem deveria fundar colégios e também algumas universidades, onde os que deram boa conta de si nas casas e foram recebidos sem os conhecimentos doutrinais necessários se possam instruir neles e nos outros meios de ajudar as almas. ${ }^{30} \mathrm{~A}$ intenção inicial era a de que esses colégios fossem destinados apenas aos candidatos a membros da Companhia, todavia, ao longo das diversas revisões das Constituições, alterou-se a entrada nos colégios, de modo a permitir que alguns leigos fossem admitidos. Assim, se esses colégios se destinavam, prioritariamente, a "pessoas de quem se possa razoavelmente esperar que se hão de tornar operários competentes na vinha de Cristo Nosso Senhor, pelo exemplo e doutrina", poderiam, no entanto, em certas condições, receber também "outros estudantes pobres que não tenham tal decisão" e ainda "filhos de pessoas ricas ou nobres, 
pagando eles as suas despesas." 31

A orientação pedagógica da Companhia de Jesus guiava-se pela indicação das disciplinas que deveriam ser estudadas, os livros que deveriam ser lidos e a condução do estudo. Com base nessa doutrina, e depois de adquirida a prática suficiente do ensino, redigiu-se um texto normativo, para uso geral, discutido em todos os pormenores até se considerar definitivo. Todo o ensino das disciplinas tinha como base a Ratio Studiorum, conforme ficou dito, programa e regulamento pedagógico da Companhia de Jesus, e instrumento de homogeneização do ensino dos Jesuítas.

Estes estudantes deveriam, todavia, comportar-se segundo as regras dos escolásticos da Companhia no que dissesse respeito às confissões, aos estudos e aos modos de vida, embora a maneira de vestir fosse diferente. Os alunos residiam numa parte separada do Colégio, podendo alguns poucos serem acolhidos a viverem com os jesuítas ou os candidatos a jesuítas. Refira-se, a este propósito, que na América Portuguesa vigorou o sistema de externatos até finais do século XVII. As Constituições da Companhia, conhecidas em terras brasis em 1556, mostravam que os meninos não podiam coabitar com os padres. Assim nasceram os externatos para os filhos dos moradores, habitando os alunos fora do colégio, com os pais. Em meados do século XVIII, os seminários começaram a ter um sentido conhecido, na contemporaneidade, de preparação exclusiva para a carreira eclesiástica, oferecendo Estudos Maiores, frequentados pelos seminaristas. ${ }^{32}$

A Ratio Studiorum foi um documento que demonstrou como a hierarquia e a disciplina eram fatores indispensáveis para a Companhia de Jesus. Este documento relativo à organização dos estudos e da espiritualidade também se dedicou a categorizar as atribuições dos colégios, regendo formas de avaliação e procedimentos diversos. A Ratio indicou desde as responsabilidades de cada função exercida dentro dos estabelecimentos de ensino jesuítico aos conteúdos a serem ministrados. A instrução deveria ser dada em ambiente rigoroso e coerente, sob severa disciplina, mas sempre pronta a ser adaptada aos outros lugares onde os colégios foram implementados, para a melhor aplicação da Ratio nas regiões missioneiras.

A Ratio Studiorum constituiu um paradigma importante para a instrução e para a pedagogia. Nas palavras de Cezar Arnaut de Toledo "mesmo não tendo definido ou explicitado princípio educacional ou pedagógico, ordenou uma razão política, que é parte constituinte na formação do mundo moderno e também razão pedagógica em sua origem e justificação." ${ }^{33}$ A Ratio mostrou, ainda, como a ação dos Jesuítas foi sempre integrada. Segundo Jose Maria de Paiva:

Ela é fundada, com efeito, numa visão unívoca do homem inteiramente endereçado para Deus, mediante a Igreja católica. Esta vocação deve realizar-se em todas 
as manifestações da vida humana. O Ratio Studiorum espelha fielmente esta univocidade de visão e, por isso, não desvincula educação de instrução, instrução de vida cristã, ciência de fé, vida profana de vida espiritual. ${ }^{34}$

A esse respeito, o objetivo repetidamente enunciado, ao longo da Ratio, é o de conhecer e amar o Criador, incorporando o princípio e o fundamento da espiritualidade inaciana. A formação do cristão não dispensava os mestres jesuítas do conhecimento e do ensino das artes liberais. ${ }^{35}$

\section{O plano de estudos da Ratio Studiorum}

O plano de estudos seguido nas escolas da Companhia de Jesus constava de três cursos: Curso de Letras, Curso de Filosofia ou Artes e Curso de Teologia. Nos colégios jesuítas praticava-se uma escolaridade que poderia ir, no mesmo colégio, do ensino das primeiras letras ao ensino de disciplinas de nível universitário. O Curso de Letras era o mais elementar de todos, e estava dividido em três partes, que correspondiam às designações de Gramática, Humanidades e Retórica. A finalidade pretendida era a aquisição de uma expressão oral e escrita corretas, mas na língua latina. Na sua origem, o nome de Humanidades foi dado pelos Jesuítas aos estudos intermediários entre os de Gramática e os de Retórica. A organização escolar que se fixou no século XVI foi a mesma para colégios seculares ou jesuíticos, e mais tarde de outras congregações, definindo cinco cursos de Humanidades: três de Gramática, um de Humanidades e um de Retórica.

Este novo modelo de ensino deveria acompanhar a criança até à idade adulta, uma educação completa, que permitia aos jovens ocupar os lugares de relevo na sociedade. Aos saberes tradicionais, acrescentavam-se a dialética e a eloquência, a crítica literária, a gramática, a prosa artística e a matemática, constituindo-se o plano de estudos que esteve na base do triuium e do quadriuium, formando as artes liberais no seu conjunto: a gramática, a retórica e a dialética; a aritmética, a geometria, a astronomia e a música. Estas seriam as bases do ensino escolar ocidental, conjugando um ensino simultaneamente científico e literário. ${ }^{36}$ Colocava-se aqui em primeiro plano o ensino e a prática da Filosofia. Este debate, presente na Grécia antiga, conheceu diversas discussões ao longo da história. Não foi apenas a noção de filosofia que se ampliou para novas concepções, mas também o patrimônio literário que enriqueceu.

Dois tipos de instrução foram oferecidos às classes dirigentes e as mais abastadas: uma fundada na natureza, na observação às coisas e ao universo, permitindo ao homem situar-se no mundo, multiplicar as suas marcas, inscrever a sua ação. A outra vertente estava apoiada em textos e a língua necessária à comunicação, à persuasão, suporte necessário e indispensável do pensamento. 
O homem que a tradição humanista formava era aquele que tinha contato com autores, com a prática dos textos, pelo exercício da tradução, da imitação e da composição, adquirindo o gosto, a capacidade crítica, a capacidade de julgamento pessoal, e a arte de se exprimir oralmento e por escrito, segundo as normas recebidas. Este ideal que se pretendeu atingir, no horizonte das Humanidades, produziu um sujeito católico, do colégio jesuíta, mas tambem um cidadão das Luzes ou um republicano dos liceus modernos. A educação das Humanidades preconizou uma educação global, em sua parte estética, retórica, mas também moral e cívica, produzindo o modelo de homem ideal da sua época ${ }^{37}$

A educação procurou sempre a transmissão de costumes formadores de adultos capazes de viver em conformidade as normas. Há, pois, a cada momento, um tipo regulador de educação do qual não nos podemos separar sem vivas resistências, e que restringem as falhas dos dissidentes. Conforme referiu Durkheim:

Em Atenas, procurava-se formar espíritos delicados, prudentes, sutis, embebidos da graça e harmonia, capazes de gozar o belo e os prazeres da pura especulação; em Roma, desejava-se especialmente que as crianças se tornassem homens de ação, apaixonados pela glória militar, indiferentes no que tocasse às letras e às artes. Na Idade Média, a educação era cristã, antes de tudo; na Renascença toma caráter mais leigo, mais literário; nos dias de hoje a ciência tende a ocupar o lugar que a arte outrora preenchia. ${ }^{38}$

A unidade do ensino era reforçada pelo fato de cada classe ser anual, ter o seu próprio professor, livros escolares comuns, métodos de ensino comuns, como a comunicação oral professor-aluno, bem como a obrigatoriedade de os apontamentos na aula serem escritos em latim. A questão pedagógica fundamental era tornar o aluno capaz de se expressar, oralmente e por escrito, na língua latina. O modelo proposto remonta ao século IV a.C. e foi fixado por Isócrates, em Atenas, herdado dos romanos. Os textos latinos, os autores romanos e os exercícios de composição em latim constituem o seu eixo do estudo de Humanidades. A partir do latim se aprendia a língua mãe e também o grego. ${ }^{39}$

Um estudante normal levaria, em média, cinco a seis anos a percorrer o plano de estudos humanísticos, mas como a Ratio permitia alguma flexibilidade nas promoções, alguns alunos poderiam completar os estudos de Humanidades em menos de 5 anos e outros poderiam precisar de mais alguns meses, ou de mais um ano. Aos estudantes jesuítas, salvo raras exceções, a Ratio exigia que completassem rigorosamente um biênio de Retórica, antes de avançarem para a Filosofia; e aos externos, o reitor tinha o dever de motivar também para aquele 
estudo, durante, pelo menos, um ano. A classe de Retórica estava, aliás, no topo do ensino das Humanidades. Toda a estrutura curricular das Humanidades convergia para esta classe, dedicada ao ensino da palavra e da eloquência, de modo a que o estudante desenvolvesse uma certa erudição sobre os preceitos da Retórica. ${ }^{40}$

O modelo educativo idealizado e defendido pelos Jesuítas implicava um novo estatuto do mestre, que deveria ser alguem detentor de autoridade moral, mas também possuidor do conhecimento, zelando para que o estudante adquirisse os comportamentos e os princípios que correspondessem à sua condição e idade. As ordens religiosas dedicadas à instrução da juventude preocuparam-se, desde muito cedo, em proporcionar aos religiosos que se ocuparam de tal função educativa uma formação especial. No caso concreto dos Jesuítas, a obra de Jouvency, De Ratione Discendi et Docendi informou qual deveria ser a imagem do professor e do discípulo. ${ }^{41} \mathrm{O}$ papel exemplar e interventivo do professor foi assunto sobre o qual o autor insistiu, no século XVII, mostrando que este não só seria modelo de conduta moral e religiosa, para o aluno, mas de igual modo deveria moldar os textos dos autores estudados nas aulas, incluindo os pagãos e os profanos, de modo a que estes fossem panegíricos de Cristo.

\section{Considerações finais}

O século XVI representou para a Igreja católica uma gama de desafios, trouxe problemas inéditos que careciam de respostas imediatas. ACompanhia de Jesus surgiu exatamente nesse contexto. A Ordem deveria colonizar, evangelizar e missionar por terras distantes. O colégio religioso cristão trabalhou com alguns conceitos educativos que são comuns, nos nossos dias. A individualização do aluno, a sua distribuição por turmas, a progressão paulatina, consoante o nível de conhecimentos, o mestre (ou professor) devidamente preparado para o processo de ensino, todos esses aspectos são novidades trazidas pelos colégios religiosos. No caso inaciano, o colégio foi elevado a uma estratégia religiosa de construção de um novo homem, católico, devoto, e com conhecimentos em diversas áreas do saber. A Companhia de Jesus apostou em instrumentos de homogeneização, como a Ratio Studiorum e o modus parisiensis, de forma a fundar colégios dentro de um mesmo ideário religioso. Mais do que isso, os colégios foram uma aposta de evangelização e globalização da Companhia.

A atenção dispensada aos mestres foi também um aspecto fulcral, nesta aposta. Assim, entendeu-se que a formação correta e exigente de um mestre seria também parte do sucesso desta empreitada. O mestre deveria intervir, diretamente, nos textos da Antiguidade Clássica, escolhendo cuidadosamente o seu objeto de estudo e de preleção em aula. 
O colégio apareceu com uma série de mecanismos pedagógicos que inculcaram no aluno um sentido de dever e de prática católica, de moldagem moral do caráter, mais dúctil e permeável às influências em tenra idade. A Companhia de Jesus apostou largamente na formação pedagógica dos seus alunos, de forma a intervir na sociedade.

\section{Notas de Fim}

1 MIRANDA, Margarida. Ratio Studiorum: uma nova hierarquia de saberes. In: CÓDIGO PEDAGÓGICO DOS JESUÍTAS. Ratio Studiorum da Companhia de Jesus. Introdução, versão portuguesa e notas de Margarida Miranda. Lisboa: Esfera do Caos, 2009, p. 28.

2 NÓVOA, António. Le Temps des Professeurs. Vols. I e II. Lisboa: Instituto Nacional de Investigação Científica, 1987, p. 105; 108.

3 SANTOS, Fernanda. O Colégio da Bahia: uma (quase) universidade na América Portuguesa (1556-1763). Lisboa: Theya editores, 2015, p. 228.

4 NÓVOA, António. Uma Educação que se diz 'Nova'. In: CANDEIAS, António; NÓVOA, António; FIGUEIRA, Manuel Henrique. Sobre a Educação Nova: cartas de Adolfo Lima a Álvaro Viana de Lemos. Lisboa: Educa, 1995, p. 27.

5 JULIA, Dominique. Disciplinas Escolares: Objetivos, Ensino e Apropriação. In: LOPES, Alice Casimiro, MACEDO, Elizabeth (orgs.). Disciplinas e Integração curricular: história e políticas. Rio de Janeiro: DP\&A editora, 2002, p. 52.

6 RAMOS DO Ó, Jorge. O Governo de Si Mesmo: modernidade pedagógica e encenações disciplinares do aluno liceal (último quartel do século XIX - meados do século XX). Lisboa: EDUCA, 2003, p. 166.

7 VARELA, Julia. Modos de Educacion en la España de la Contrarreforma. Madrid: Las Ediciones de La Piqueta, 1983, p. 131.

8 PETITAT, André. Produção da Escola/Produção da Sociedade: análise sócio-histórica de alguns momentos decisivos da evolução escolar no Ocidente. Porto Alegre: Artes Médicas, 1994, p. 77.

9 MIRANDA, Margarida. Op.Cit., p. 23.

10 ARIÈS, Phillipe. História Social da Família e da Criança. 2. ${ }^{a}$ ed. Rio de Janeiro: Guanabara, 1981, p. 110-111.

11 MIRANDA, Margarida. Op.Cit., p. 34.

12 DURKHEIM, Émile. A Evolução Pedagógica. Porto Alegre: Artes Médicas, 1995, p. 51.

13 Ibidem, p. 31.

14 ELIAS, Norbert. O Processo Civilizador: formação do Estado e Civilização. Trad. Ruy Junomann. Rio de Janeiro: Jorge Zahar Editor, vol 2, 1998, p. 196.

15 HAMILTON, David. Towards a Theory of Schooling. London, New York, Philadelphia: The Falmer Press, 1989, p. 18-19.

16 REVEL, Jaques. Os usos da civilidade. In: ARIÈS, Philippe, CHARTIER, Roger (orgs.). História da Vida Privada - Da Renascença ao Século das Luzes. Trad. Hildegard Feist. São Paulo: Companhia de Bolso, vol. 3, 2009, p. 170-171. 
17 VARELA, Julia. Op.Cit., p. 157.

18 MIRANDA, Margarida. Op.Cit., p. 34.

19 WRIGHT, Jonathan. Os Jesuitas: as Missões, Mitos e Histórias. Rio de Janeiro: editora Relume, 2006, p. 58.

20 FRANCO, José Eduardo. Século XVI. In: FRANCO, José Eduardo, CALAFATE, Pedro (coord.). A Europa segundo Portugal: Ideias de Europa na Cultura Portuguesa, século a século. Lisboa: Gradiva, 2012, p. 44.

21 WRIGHT, Jonathan. Op.Cit., p. 21-22; 24.

22 ARNAUT DE TOLEDO, Cézar de Alencar; RUCKSTADTER, Flávio Massami Martins. A Filosofia Educacional dos Jesuítas nas Cartas do Pe. José de Anchieta. In: Acta Scientiarum. Maringá, vol. 25, n. ${ }^{\circ}$ 2, 2003, p. 143.

23 HANSEN, João Adolfo. Ratio Studiorum e Política Católica Ibérica no Século XVII. In: VIDAL, Diana Gonçalves; HILSDORF, Maria Lúcia Spedo (orgs). Tópicos em História da Educação. São Paulo: Editora da Universidade de São Paulo, 2001, p. 24-26.

24 VARELA, Julia. Op.Cit., p. 132-133.

25 GOMES, Manuel Pereira, s.j. Sto. Inácio e a Fundação de Colégios. Gracos, 1996, p. 85.

26COMPÈRE, Marie-Madeleine. Du Collège au Lycée (1500-1850). Paris : éditions Gallimard/ Julliard, 1976, p. 24.

27 MIR, Gabriel Codina. Aux Sources de la Pédagogie des Jésuites. Le Modus Parisiensis. Roma: Institutum Historicum Societatis Jesu, 1968, p. 261-262.

28 RAMOS DO O, Jorge. Op. Cit., p. 167.

29 MIRANDA, Margarida. Op.Cit., p. 28.

30 LOYOLA, Inácio de. Constituições da Companhia de Jesus e Normas Complementares. Op. Cit., parte IV, parágrafo 307, p. 115.

31 Ibidem, p. 115-116.

32 LEITE, Serafim. História da Companhia de Jesus no Brasil. Rio de Janeiro: Instituto Nacional do Livro, tomo X, 1949, p. 222-223. LEITE, Serafim. História da Companhia de Jesus no Brasil. Rio de Janeiro: Instituto Nacional do Livro, tomo VII, 1949, p. 375.

33 ARNAUT DE TOLEDO, Cézar de Alencar. Razão de Estudos e Razão Política: um estudo sobre a Ratio Studiorum. In: Acta Scientiarum. Maringá, vol. 22, n. ${ }^{\circ}$ 1, 2000, p. 182.

34 PAIVA, José Maria de. O Método Pedagógico Jesuítico: uma análise do Ratio Studiorum. Viçosa: Oficinas Gráficas da Imprensa Universitária da Universidade Federal de Viçosa, 1981, p. 17.

35 CÓDIGO PEDAGÓGICO DOS JESUÍTAS. Ratio Studiorum da Companhia de Jesus. Introdução, versão portuguesa e notas de Margarida Miranda. Lisboa: Esfera do Caos, 2009, p. 58.

36 MIRANDA, Margarida. Op.Cit., p. 18.

37 CHERVEL, André, COMPÈRE, Marie-Madeleine. As Humanidades no Ensino. Educação e Pesquisa. São Paulo: Universidade de São Paulo, vol. 25, n. ${ }^{\circ}$ 2, p. 149-170, 1999, p. 149-150.

38 DURKHEIM, Émile. Educação e Sociologia. Trad. Lourenço Filho. 4. ${ }^{a}$ ed. São Paulo: Edições Melhoramentos, 1955, p. 27. 
39 CHERVEL; Andre; COMPERE, Marie-Madeleine. Op.Cit., p. 149-150.

40 MIRANDA, Margarida. Op.Cit., p. 29-30.

41 JOUVENCY, J. De la Maniere d'Apprendre et d'Enseigner (De Ratione Discendi et Docendi). Paris: Hachette, 1900, p. 85-86.

Artigo recebido em junho de 2017. Aceito em julho de 2017. 